\title{
Simultaneous prescribing of atypical antipsychotics, conventional antipsychotics and anticholinergics-a European study
}

\author{
W. J. Broekema $\cdot$ I. W. de Groot $\cdot$ P. N. van Harten
}

Received: 5 May 2004 / Accepted: 30 November 2005/ Published online: 27 February 2007

(C) Springer Science+Business Media B.V. 2007

\begin{abstract}
Objective The aim of this study was to investigate to what extent atypical antipsychotics, conventional antipsychotics and anticholinergics are prescribed simultaneously in daily clinical practice in Europe.

Method A pharmaco-epidemiological study was carried out in which hospital pharmacists from 45 hospitals in Belgium, Denmark, France, Germany, The Netherlands and Scotland participated. Prescription data for 2,725 patients (mainly inpatients) who had been using an atypical antipsychotic for more than 6 weeks were analysed.

Main outcome measure The frequencies of simultaneous prescription of atypical antipsychotics with other antipsychotics and/or anticholinergics.

Results In this sample of patients with an atypical antipsychotic $42.1 \%$ was prescribed another antipsychotic $(24.1 \%$ if low-potent antipsychotics were not included in the analysis) and $30.1 \%$ was prescribed an anticholinergic. In total $47.1 \%$ of patients were prescribed an atypical antipsychotic without any other antipsychotic or anticholinergic.

Conclusion It is common practice to prescribe a combination of atypical antipsychotics and conventional
\end{abstract}

Springer apologises for the long period that it took to prepare this paper for publication

W. J. Broekema · I. W. de Groot · P. N. van Harten Symfora group, Centres for Mental Healthcare, Amersfoort, The Netherlands

\section{W. J. Broekema $(\bowtie)$}

Symfora groep, locatie Zon \& Schild, Apotheek, Medisch Centrum, P.O. Box 3051, NL-3800 DB Amersfoort, The Netherlands

e-mail: wj.broekema@symfora.nl antipsychotics and/or anticholinergics. This suggests that monotherapy involving an atypical antipsychotic is not considered to be an adequate treatment for a substantial number of patients in clinical practice.

Keywords Anticholinergics - Antipsychotic agents · Drug therapy combination - Drug use study . Europe · Pharmaco-epidemiology · Polypharmacy

\section{Introduction}

All antipsychotics are solely registered for use as monotherapy. The prescription of two or more antipsychotics simultaneously, also called antipsychotic polypharmacy, has no empirical foundation [1]. However, in the past antipsychotic polypharmacy with two conventional ('early generation') antipsychotics was frequently practised with reported frequencies ranging from approximately $10-69 \%$ [2]. In the last years the conventional antipsychotics are increasingly replaced by the atypical ('second generation') antipsychotics. Few studies from the UK and the US have focused on antipsychotic polypharmacy with atypical antipsychotics and reported frequencies ranging from $13 \%$ to $68 \%$ [3-7].

We carried out a pharmaco-epidemiological study to atypical antipsychotic polypharmacy and included data of patients of several psychiatric hospitals in various European countries. Additionally, we also focused on the co-prescription of anticholinergic drugs. There is considerable evidence that atypical antipsychotics cause fewer extrapyramidal side effects than conventional antipsychotics [8]. Therefore, there should be less need for anticholinergic co-medication to be prescribed with the atypicals. 
This European study was conducted to investigate to what extent atypical antipsychotics, conventional antipsychotics and anticholinergics are being prescribed simultaneously in daily clinical practice.

\section{Method}

The study was carried out with the co-operation of members of the 'European Pharmacists for Psychiatry and Neurology' (EPPN), an organisation of hospital pharmacists working in psychiatry and neurology. All participating hospital pharmacists were working in psychiatric hospitals. Data were collected between November 1998 and October 1999. In that period the hospital pharmacists screened their hospital pharmacy database on one single day for patients who had been using an atypical antipsychotic for a minimum of 6 weeks. The 6 -week period was chosen so that titration to the atypical antipsychotic should have been completed. No restrictions were imposed with regard to age and diagnosis.

The following data were collected for each patient included: age, sex, type and dose of the atypical(s) and, if prescribed, type and dose of conventional antipsychotics (maximum of four) and the type of anticholinergics (maximum of four). "As needed" (PRN) medication was considered as "used" medication. The doses of antipsychotic depot-medications were recalculated to daily oral doses [9]. All data were checked for improbable doses, duplication of patients and other errors.

Median doses of the antipsychotics are given, because of positively skewed distributions. The frequencies with which antipsychotic polypharmacy was practised and anticholinergics were prescribed are calculated for the total group of patients and per individual atypical antipsychotic.

Conventional antipsychotics with a chlorpromazine equivalent dose of more than $40 \mathrm{mg}$ (compared to $100 \mathrm{mg}$ chlorpromazine) are considered to be low potency drugs $[10,11]$. The frequencies with which anti- psychotic polypharmacy was practised are calculated with and without the low-potent antipsychotics.

\section{Results}

Hospital pharmacists from six West European countries participated: Belgium, Denmark, France, Germany, The Netherlands and Scotland. In total, data were received for 2,765 patients. Of these, 40 patients $(1.5 \%)$ were excluded for the following reasons: patients mentioned twice $(n=10)$, no atypical antipsychotic prescribed $(n=8)$, improbably low clozapine doses $(n=5)$ and other errors $(n=17)$.

Table 1 shows details of the participating countries and patients. Most patients came from Belgium $(40.9 \%)$, followed by The Netherlands $(26.2 \%)$ and France $(16.5 \%)$.

Table 2 shows the frequencies with which the atypical antipsychotics were prescribed, the median dose, the frequencies with which of antipsychotic polypharmacy (with and without the low-potent conventional antipsychotics) was practised, the frequencies with which anticholinergics were administrated and the frequencies of no co-prescription of antipsychotics or anticholinergics.

Risperidone was prescribed most often $(40.2 \%)$, followed by clozapine (25.1\%), olanzapine (20.6\%) and others (in total $14.1 \%$ ). For 65 patients $(2.4 \%) 2$ atypical antipsychotics were prescribed; the combinations used most were clozapine/risperidone $(n=18)$, olanzapine/risperidone $(n=12)$ and sulpiride/risperidone $(n=11)$. In our population of patients using an atypical, antipsychotic polypharmacy was prescribed in $42.1 \%$ of cases. Of patients receiving antipsychotic polypharmacy $31.7 \%, 8.5 \%, 1.3 \%$ and $.6 \%$ were prescribed two, three, four, and five or more antipsychotics respectively.

Table 3 shows the antipsychotics prescribed concurrently with the atypicals. The conventional antipsychotics prescribed most often were levomepromazine, haloperidol, prothipendyl, cyamemazine and zuclopentixol. When the low-potent conventional
Table 1 Number of hospitals and patients included in the participating countries with the mean age of patients and the percentages of male patients

\begin{tabular}{lcccc}
\hline Country & Number of hospitals $(\%)$ & Number of patients (\%) & Mean age (sd) & $\%$ of males \\
\hline Belgium & $19(42.2 \%)$ & $1115(40.9 \%)$ & $47.9(15.6)$ & $59 \%$ \\
The Netherlands & $5(11.1 \%)$ & $715(26.2 \%)$ & $46.1(17.9)$ & $54 \%$ \\
France & $10(22.2 \%)$ & $449(16.5 \%)$ & $42.3(14.5)$ & $61 \%$ \\
Denmark & $4(8.9 \%)$ & $217(8.0 \%)$ & $48.1(16.4)$ & $52 \%$ \\
Scotland & $6(13.3 \%)$ & $183(6.7 \%)$ & $45.8(17.7)$ & $51 \%$ \\
Germany & $1(2.2 \%)$ & $46(1.7 \%)$ & $38.5(13.9)$ & $60 \%$ \\
Total & $45(100 \%)$ & $2725(100 \%)$ & $46.2(16.4)$ & $57 \%$ \\
\hline
\end{tabular}


Table 2. Details of the atypical antipsychotics prescribed: their frequencies; median dose; the frequencies of patients prescribed antipsychotic polypharmacy (with and without low-potent antipsychotics) and anticholinergics; the frequencies of no coprescription of antipsychotics and anticholinergics $(n=2,725)$

\begin{tabular}{|c|c|c|c|c|c|c|}
\hline $\begin{array}{l}\text { Atypical } \\
\text { antipsychotic }\end{array}$ & $\begin{array}{l}\text { Number of } \\
\text { patients }(\%)\end{array}$ & $\begin{array}{l}\text { Median } \\
\text { dose } \\
(\mathrm{mg})\end{array}$ & $\begin{array}{l}\text { Antipsychotic polypharmacy } \\
\text { (\%) (including low-potent } \\
\text { antipsychotics) }\end{array}$ & $\begin{array}{l}\text { Antipsychotic } \\
\text { polypharmacy } \\
\text { (\%) (excluding } \\
\text { low-potent } \\
\text { antipsychotics)* }\end{array}$ & $\begin{array}{l}\text { Anticholinergic } \\
\text { prescription } \\
(\%)\end{array}$ & $\begin{array}{l}\text { No co-prescription } \\
\text { of antipsychotics or } \\
\text { anticholinergics (\%) }\end{array}$ \\
\hline Risperidone & $1095(40.2 \%)$ & 4.0 & 45.1 & 24.7 & 36.5 & 42.0 \\
\hline Clozapine & $683(25.1 \%)$ & 400.0 & 31.2 & 18.9 & 24.5 & 57.7 \\
\hline Olanzapine & $562(20.6 \%)$ & 15.0 & 37.0 & 22.1 & 20.3 & 56.2 \\
\hline Sulpiride & $133(4.9 \%)$ & 300.0 & 49.2 & 25.8 & 31.1 & 41.7 \\
\hline Amisulpride & $132(4.8 \%)$ & 600.0 & 54.1 & 23.3 & 45.9 & 28.6 \\
\hline Sertindole & $37(1.4 \%)$ & 16.0 & 62.2 & 24.3 & 27.0 & 29.7 \\
\hline Quetiapine & $16(0.6 \%)$ & 550.0 & 50.0 & 12.5 & 12.5 & 43.8 \\
\hline Zotepine & $2(0.1 \%)$ & 225.0 & 0 & 0 & 0 & 100 \\
\hline Two atypicals & $65(2.4 \%)$ & $* *$ & $* * *$ & $* * *$ & 40.0 & $* * * *$ \\
\hline Total & $2725(100 \%)$ & - & $42.1 \%$ & $24.4 \%$ & $30.1 \%$ & $47.1 \%$ \\
\hline
\end{tabular}

* See Table 3 for the classification of the low-potent antipsychotics

** Total median dose not calculated

*** By definition $100 \%$

**** By definition $0 \%$

Table 3 The frequencies and median doses antipsychotics prescribed concurrently for patients using atypical antipsychotics

\begin{tabular}{lll}
\hline Antipsychotic & $\begin{array}{l}\text { Antipsychotic } \\
\text { scribed } \\
\text { concurrently }(\%)\end{array}$ & $\begin{array}{c}\text { pre- } \\
\text { dose } \\
(\mathrm{mg})\end{array}$ \\
\hline Levomepromazine* & $16.6 \%$ & 50.0 \\
Haloperidol & $11.2 \%$ & 10.0 \\
Prothipendyl* & $9.5 \%$ & 80.0 \\
Cyamemazine* & $7.1 \%$ & 100.0 \\
Zuclopenthixol & $7.6 \%$ & 28.5 \\
Pipamperon* & $5.6 \%$ & 80.0 \\
Dehydrobenzperidol & $4.7 \%$ & 10.0 \\
Thioridazine* & $4.4 \%$ & 100.0 \\
Clotiapine & $4.4 \%$ & 40.0 \\
Chlorpromazine* & $3.1 \%$ & 200.0 \\
Flupenthixol & $2.7 \%$ & 5.9 \\
Fluphenazine & $2.4 \%$ & 9.0 \\
Bromperidol & $2.4 \%$ & 7.5 \\
Chlorprothixeen* & $1.8 \%$ & 100.0 \\
Perphenazine & $1.5 \%$ & 16.0 \\
Pimozide & $1.4 \%$ & 4.0 \\
Other conventional & $9.2 \%$ & - \\
antipsychotics & & \\
Second atypical & $4.2 \%$ & - \\
Total & $100.0 \%$ & - \\
\hline
\end{tabular}

* Considered as low-potent antipsychotic

antipsychotics are not included in the analysis, $24.4 \%$ of the patients was prescribed antipsychotic polypharmacy.

In total $30.1 \%$ of the patients were prescribed an anticholinergic drug. The anticholinergics prescribed most often were biperiden $(28.3 \%)$, procyclidine $(19.9 \%)$, trihexyphenidyl $(16.7 \%)$ and tropatepine $(13.4 \%)$.
In total $47.1 \%$ of the patients are prescribed the atypical antipsychotic without any other antipsychotic or anticholinergic, $22.8 \%$ are prescribed an atypical plus one or more other antipsychotics, $10.8 \%$ are given an atypical plus an anticholinergic and $19.3 \%$ an atypical plus an anticholinergic and one or more other antipsychotics.

\section{Discussion}

This European study clearly shows that it is common clinical practice to prescribe an atypical antipsychotic and one or more other antipsychotics simultaneously. Low-potent antipsychotics may be added to an atypical antipsychotic mainly because of their sedative, anxiolytic and anticholinergic properties, rather than because of their antipsychotic properties. Even when the low-potent conventional antipsychotics are not included in the analysis, we found that antipsychotic polypharmacy was prescribed for almost a quarter of the patients. Additionally, we did not expect to find that almost a third of the patients were prescribed an anticholinergic in addition to the atypical drug. The results of this study imply that more than half $(52.9 \%)$ of the patients are not being treated in the way according to the psychiatric handbooks and guidelines: The atypical is frequently combined with another antipsychotic and/or an anticholinergic.

Several studies have shown that antipsychotic polypharmacy with two conventional antipsychotics was in 
frequent use in clinical practice [2]. Others have shown that fairly large numbers of patients (ranging from $18.5 \%$ to $56 \%$ ) are being prescribed a therapy that combines clozapine with a conventional antipsychotic [12-14]. Recently, a few studies have focused on antipsychotic polypharmacy with the atypical antipsychotics, with reported frequencies ranging from $13 \%$ to $68 \%$ [3-7]. There could be several reasons to explain this large variation in co-prescribing such as the definition of antipsychotic polypharmacy, whether inpatients or outpatients were included, stage of the disease, the differences in prescription patterns between countries and hospitals and different use of guidelines.

We consider several hypotheses for the relatively high rate of antipsychotic polypharmacy involving atypicals. First of all, it could be that the patients with an inadequate treatment response to one antipsychotic are treated with combinations of antipsychotics, including the atypical antipsychotics. However, there are hardly any studies that show that antipsychotic polypharmacy is effective in patients who do not respond to one antipsychotic [1].

Secondly, it is also possible that antipsychotic polypharmacy is continued although the patient shows no improvement because psychiatrists are hesitant to discontinue any medication in patients with persistent psychotic symptoms.

Thirdly, it could be that in some patients the recommended doses of the atypical antipsychotics are too low to be effective and that adding a second antipsychotic is in fact a dose-increase strategy. In such cases, however, a higher dose of one particular atypical might be just as effective.

Fourthly, when switching between two antipsychotics it is common to titrate the first drug downwards while simultaneously titrating the second drug upwards. If the patient responds halfway through the titrating process the clinician might decide to continue both antipsychotics - a situation referred to as "the cross-titration trap" [15]. Our study included only patients who had been using an atypical antipsychotic for more than 6 weeks, so the titrating process would normally have been completed.

It is remarkable that the potential risks of antipsychotic polypharmacy have received limited research attention [16]. However, Waddington et al. [17] found that antipsychotic polypharmacy is associated with reduced survival among patients with schizophrenia. Centorrino et al. [16] reports that the risk of adverse effects is $56 \%$ higher with antipsychotic polypharmacy.

There have been previous reports of anticholinergics being added to atypical antipsychotics. Of patients using clozapine 19\% [12] and 37\% [14] were also prescribed anticholinergics. Anticholinergics were added to $54.9 \%$ of patients using atypical antipsychotics [3]. These numbers are in line with our finding (30.1\%). The prescription of this combined therapy could be attributed to the use of a second, almost always conventional, antipsychotic (19.3\%), which might induce extrapyramidal symptoms. But nevertheless, $10.8 \%$ of patients are prescribed an atypical antipsychotic in combination with an anticholinergic without any other (conventional) antipsychotics. Minzenberg et al. [18] studied the effects of anticholinergic properties of psychiatric medications and found clinically significant effects on memory and complex attention.

The frequencies of atypical polypharmacy in the separate countries range between $26.1 \%$ (Germany) and $49.1 \%$ (Belgium), without the low-potent antipsychotics it varies between $17.1 \%$ (Denmark) and $31.6 \%$ (Belgium). However, these numbers should be appraised cautiously because this study was not primary set up to detect differences between the various countries (some countries are under represented).

Furthermore, the study does not allow to draw inferences about differences between the various atypicals in antipsychotic polypharmacy and anticholinergic use. These differences could easily be biased as a result of the different introduction data of the atypicals in the diverse countries. For example, at the moment of data-collection olanzapine and sertindole had been introduced very recently in most countries, quetiapine was available only in Scotland and zotepine was used only in a clinical trial.

Nevertheless, the similarity between the frequencies with which antipsychotic polypharmacy is prescribed for the various atypicals (excluding quetiapine and zotepine, on account of their low frequencies) is remarkable: Excluding low-potent antipsychotics the frequencies range from $18.9 \%$ to $25.8 \%$.

The study however has its limitations.

First of all, the population included is not a random sample from Western European countries that participated. Therefore, hypothetically it could be argued that the results were biased because only hospitals practising extremely high rates of antipsychotic polypharmacy were included. However, it is unlikely that only such hospitals were selected.

Secondly, we estimate, on the basis of the information obtained from the participating hospitals, that $90 \%$ of the data are from inpatients. The symptomatology of inpatients may be more severe than that of outpatients, and such patients may be prescribed antipsychotic polypharmacy more frequently than outpatients [3]. 
Thirdly, we did regard PRN-medication as "used" medication. This may have heightened our results somewhat but cannot explain the frequent prescription of antipsychotic polypharmacy. A major advantage of this study is the large number of patients included and the differentiation made between high- and low-potent antipsychotics. This makes extrapolation more feasible.

\section{Conclusion}

It is common practice to prescribe a combination of atypical and conventional antipsychotics. Furthermore, the use of atypical antipsychotics does rule out the use of anticholinergics. On the contrary, atypical antipsychotics are often prescribed in combination with anticholinergics. Apparently, monotherapy involving the atypicals is not considered to be an effective therapy for a substantial number of patients in clinical practice.

\section{Possible conflicts of interest}

P.N. van Harten gives lectures on symposia and congresses that are sponsored by pharmaceutical companies.

Acknowledgements We wish to thank the board and the participating members of the 'European Pharmacists for Psychiatry and Neurology' (EPPN), especially the following co-ordinating hospital pharmacists: Fernand Mathot and Johan Reijntens (Belgium), Astrid Dyssegaard (Denmark), Jacqueline Surugue (France) and Morag Martin (Scotland).

\section{References}

1. Freudenreich O, Goff DC. Antipsychotic combination therapy in schizophrenia. A review of efficacy and risks of current combinations. Acta Psychiatr Scand 2002;106(5):323330

2. Procyshyn RM, Kennedy NB, Tse G, Thompson B. Antipsychotic polypharmacy: a survey of discharge prescriptions from a tertiary care psychiatric institution. Can J Psychiatr 2001;46(4):334-9

3. Taylor D, Mace S, Mir S, Kerwin R. A prescription survey of the use of atypical antipsychotics for hospital inpatients in the United Kingdom. Int $\mathrm{J}$ Psychiatr Clin Pract 2000;4(1):41-6
4. Paton C, Lelliott P, Harrington M, Okocha C, Sensky T, Duffett R. Patterns of antipsychotic and anticholinergic prescribing for hospital inpatients. J Psychopharmacol 2003;17(2):223-9

5. Tapp A, Wood AE, Secrest L, Erdmann J, Cubberley L, Kilzieh N. Combination antipsychotic therapy in clinical practice. Psychiatr Serv 2003;54(1):55-9

6. Jaffe AB, Levine J. Antipsychotic medication coprescribing in a large state hospital system. Pharmacoepidemiol Drug Saf 2003;12(1):41-8

7. Grohmann R, Engel RR, Geissler KH, Ruther E. Psychotropic drug use in psychiatric inpatients: Recent trends and changes over time-data from the AMSP study. Pharmacopsychiatry 2004;37(3, suppl 1):27-38

8. Geddes J, Freemantle N, Harrison P, Bebbington P. Atypical antipsychotics in the treatment of schizophrenia: systematic overview and meta-regression analysis. BMJ 2000;321(7273):1371-6

9. Schulz P, Rey MJ, Dick P, Tissot R. Guidelines for the dosage of neuroleptics. II: Changing from daily oral to long acting injectable neuroleptics. Int Clin Psychopharmacol 1989;4(2):105-14

10. Siegfried SL, Fleischhacker W, Lieberman JA. Pharmacological treatment of schizophrenia. In: Lieberman JA, Murray RM, editors. Comprehensive care of schizophrenia, a textbook of clinical management. London: Martin Dunitz Ltd; 2001. ISBN 1-85317-893-4

11. Atkins M, Burgess A, Bottomly C, Riccio M. Chlorpromazine equivalents: a consensus of opinion for both clinical and research applications. Psych Bull 1997;21:224-6

12. Peacock L, Gerlach J. Clozapine treatment in Denmark: concomitant psychotropic medication and hematologic monitoring in a system with liberal usage practices. J Clin Psychiatr 1994;55(2):44-9

13. Naber D, Holzbach R, Perro C, Hippius H. Clinical managment of clozapine patients in relation to efficacy and side effects. Br J Psychiatr 1992;160(17, suppl):54-9

14. Povlsen UJ, Noring U, Fog R, Gerlach J. Tolerability and therapeutic effect of clozapine: a retrospective study of 216 patients treated with clozapine for up to 12 years. Acta Psychiatr Scand 1985;71:176-85

15. Stahl SM. Antipsychotic polypharmacy, part 1: Therapeutic option or dirty little secret? J Clin Psychiatr 1999;60(7):425-6

16. Centorrino F, Goren JL, Hennen J, Salvatore P, Kelleher JP, Baldessarini RJ. Multiple versus single antipsychotic agents for hospitalized psychiatric patients: case-control study of risks versus benefits. Am J Psychiatr 2004;161(4):700-6

17. Waddington JL, Youssef HA, Kinsella A. Mortality in schizophrenia. Antipsychotic polypharmacy and absence of adjunctive anticholinergics over the course of a 10-year prospective study. Br J Psychiatr 1998;173(10):325-9

18. Minzenberg MJ, Poole JH, Benton C, Vinogradov S. Association of anticholinergic load with impairment of complex attention and memory in schizophrenia. Am J Psyhiatr 2004;161(1):116-24 